\title{
SÍNTESE DE NANOPARTÍCULAS DE POLI(METACRILATO DE METILA) (PMMA) CARREGADAS COM LAURIL GALATO E AVALIAÇÃO DA CITOTOXICIDADE EM CÉLULAS LEUCÊMICAS MONOCÍTICAS AGUDAS (THP1)
}

\author{
P. E. FEUSER ${ }^{1}$, M. STEINDEL ${ }^{2}$, C. SAYER ${ }^{1}$ e P.H. H. de ARAÚJO ${ }^{1}$ \\ ${ }^{1}$ Universidade Federal de Santa Catarina, Departamento de Engenharia Química e Engenharia de \\ Alimentos \\ ${ }^{2}$ Universidade Federal de Santa Catarina, Departamento de Microbiologia e Parasitologia \\ E-mail para contato: pedro@enq.ufsc.br
}

RESUMO - O ácido gálico, ácido 3,4,5-trihidroxibenzóico, é um composto fenólico trihidroxilado encontrado de forma abundante no reino vegetal, sendo usado como aditivos e sequestrantes de espécies de oxigênio reativo para prevenir mudanças no sabor e no valor nutritivo devido à oxidação de ácidos graxos insaturados. O objetivo deste trabalho é a síntese e a caracterização de nanopartículas de poli(metacrilato de metila) (PMMA) carregadas com lauril galato via polimerização em miniemulsão e avaliação da citotoxicidade em células leucêmicas monicíticas agudas (THP1). O tamanho médio das Nanopartículas poliméricas foi estimado em100 nm com uma superfície de carga negativa $(-38 \mathrm{mV})$. Os ensaios de citotoxicidade com células THP1 apresentaram resultados promissores com uma $\mathrm{CL}_{50}$ (concentração letal para 50\% das células) de aproximadamente $8 \mu \mathrm{M}$.

\section{INTRODUÇÃO}

A liberação controlada (prolongada e/ou modulada) de fármacos vem sendo alvo de estudos há algumas décadas, sendo que estes estudos ganharam impulso na década passada com o aprimoramento das técnicas de micro e nanoencapsulamento. Uma das áreas mais promissoras é a de vetorização de fármacos. Dentre os vetores, incluem-se as micropartículas e os sistemas coloidais como os lipossomas e as nanopartículas poliméricas. O encapsulamento de fármacos utilizando nanopartículas poliméricas ajuda a aumentar a estabilidade, entregar o fármaco diretamente no sitio de ação desejado, controlar a liberação e dependendo do campo de aplicação apresenta algumas vantagens em relação a outros sistemas nanopartículados (SOPPIMATH et al, 2000). As primeiras nanopartículas poliméricas para aplicação biomédica foram descritas no final da década de 60 e inicio dos anos 70. Nanopartículas poliméricas tem aplicações destacada na terapia de doenças crônicas, como na liberação controlada de fármacos nas células ou tecido alvo, sendo este um grande obstáculo no desenvolvimento de novos sistemas nanopartículados. Este é particularmente problemático para fármacos antineoplásico, que são tipicamente compostos hidrofóbicos com perfis farmacocinéticos pobres e exigindo, portanto, repetidas administração para alcançar uma dose adequada (ABULATEEFEH et al, 2013). 


\section{9 a 22 de outubro de 2014 \\ Florianópolis/SC}

Existem vários métodos relatados na literatura para a preparação de nanopartículas poliméricas, os quais podem ser de uma forma geral, classificados em métodos baseados na polimerização in situ de monômeros dispersos ou na precipitação de polímeros pré-formados (SCHAFFAZICK et al, 2002). Entre os principais métodos para preparação de nanopartículas poliméricas in situ pode-se citar a polimerização interfacial, a polimerização em emulsão e a polimerização em miniemulsão. Já dentre as técnicas que evolvem polímeros pré-formados podese destacar os método de nanoprecipitação e emulsificação e evaporação de solvente. A técnica de polimerização em miniemulsão é classicamente definida como sendo constituída por dispersões aquosas de gotículas de óleo relativamente estáveis, dentro de uma faixa de tamanhos de 50-500 nm preparadas por um sistema contendo óleo, água, surfactante e um co-estabilizador (LANDFESTER, 2009; REIS et al, 2006; SHORK et al, 2005).

O ácido gálico é um composto fenólico trihidroxilado e uma molécula encontrada de forma abundante no reino vegetal como um metabólito secundário (antioxidante natural), componente de taninos hidrolisáveis em uvas e chás (TONINI, 2013). Taninos são uma importante classe de polifenóis e não é apenas uma parte integrante da alimentação humana, mas também são encontrados em medicamentos fitoterápicos tradicionais (KOLODZIEJ et al; YANG et al; 2008, 2006). Suas aplicações incluem-se como aditivos e sequestrantes de espécies de oxigênio reativo para prevenir mudanças no sabor e no valor nutritivo devido à oxidação de ácidos graxos insaturados (SAKAGAMI et al, 1997; KOLODZIEJ; et al, 2008; LOCATELLI et al, 2013). Outras aplicações importantes dos AG e os galatos de alquila é a sua atividade antitumoral (LOCATELLI et al, 2008; LOCATELLI et al, 2009; LU et al, 2006), antiparasitaria (KOIDE et al, 1998), antimicrobiana e antiviral (LOCATELLI et al, 2013). Alguns ésteres de AG ou galatos de alquilas como, os galatos de octila (G8) e lauril galato (G12), são amplamente utilizados como aditivos alimentares na indústria farmacêutica e cosmética desde 1947.

Neste contexto, este trabalho visa o encapsulamento do lauril galato (G12) em nanopartículas de poli(metacrilato de metila), PMMA, via polimerização em miniemulsão e sua caracterização e por fim a avaliação da citotoxicidade em linhagem de células leucêmicas monocíticas agudas (THP1).

\section{MATERIAIS E MÉTODOS}

Para a preparação das nanopartículas de PMMA utilizou-se o Lauril galato (G12) e Nmetil-2-pirrolidona ambos da Sigma Aldrich. O monômero metacrilato de metila (MMA) adquirido da ARINOS Química, como iniciador o AIBN (2,2'azo bis-isobutironitrila) (VETEC química), como surfactante a lecitina (Alfa Aesar), como co-surfactante o miglyol 812 (Sazol) e água destilada. No preparo da miniemulsão utilizou-se um homogenizador Fisher Scientific (Sonic Dismembrator Model 500). Este equipamento é constituído de um gerador, um conversor e uma sonda, através da qual são emitidas ondas produzindo uma cavitação no sistema que resulta no rompimento das gotas.

Para o encapsulamento do G12 em nanopartículas de PMMA via polimerização em miniemulsão (PMMA/G12) utiliza-se um béquer de $100 \mathrm{~mL}$ e adiciona-se a fase aquosa (apenas a água). O dispersor é ligado (etapa 1) e adiciona-se a fase orgânica (lauril galato solubilizado em NMP (50mg/mL), monômero, surfactante, co-surfactante e iniciador) (etapa 2). O tempo de sonicação é de 5 minutos sem pausa com uma amplitude de $70 \%$. A próxima etapa é o processo 
de homopolimerização, onde se utilizou um banho termocriostático a uma temperatura de $75^{\circ} \mathrm{C}$ até a sua completa polimerização (etapa 3). Em seguida, o material é resfriado, centrifugado e lavado várias vezes com água destilada (etapa 4). Na próxima etapa o material é seco em estufa a uma temperatura pré-definida $\left(60^{\circ} \mathrm{C}\right)$ por um período de $24 \mathrm{hrs}$ (etapa 5). A Figura 1 ilustra o procedimento para o encapsulamento do G12 em nanopartículas de PMMA.

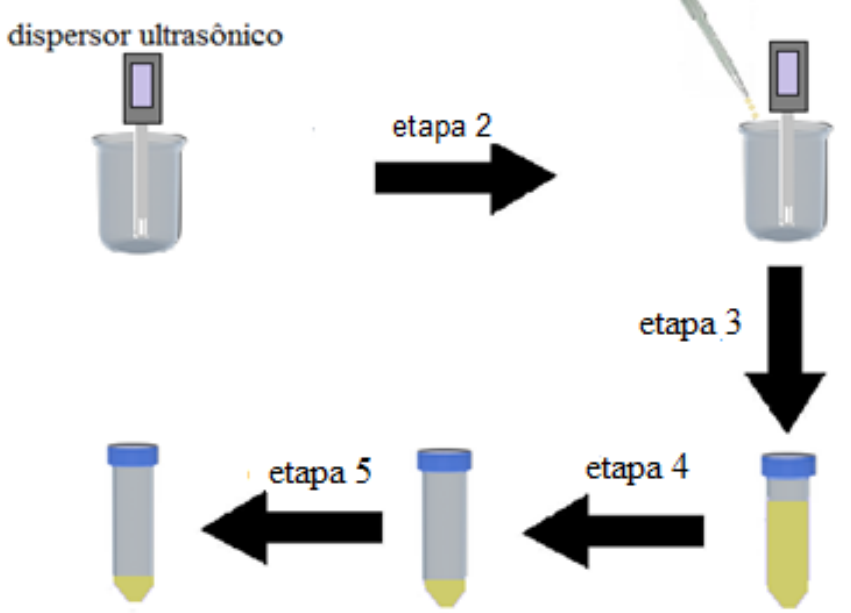

Figura 1 - Ilustração do encapsulamento do G12 em nanopartículas de PMMA via polimerização em miniemulsão.

Para análise da morfologia das nanopartículas poliméricas utilizou-se a técnica de microscopia eletrônica de transmissão (MET) JEOL, modelo JEM-1011. A técnica de espalhamento dinâmico de luz, DLS foi usada para determinar o tamanho médio de partícula e o índice de polidispersão. Para a análise da carga superficial das nanopartículas poliméricas utilizou-se o Zetasizer. Nos ensaios de citotoxicidade utilizaram-se linhagens de células THP1 e a viabilidade celular foi analisada utilizando um ensaio colorimétrico de sal brometo de 3-(4,5dimetiltiazol-2-il)-2-5-difeniltetrazolium (MTT) que se baseia na redução do MTT ao seu derivado formazan de cor azulada pelo metabolismo mitocondrial.

\section{RESULTADOS E DISCUSSÃO}

A morfologia das nanopartículas de PMMA contendo G12 foi avaliada via MET (Figura 2). Esta análise permitiu verificar a presença de nucleações secundárias que poderiam promover a formação de novas partículas sem a incorporação do fármaco, podendo causar um alargamento da DTP que nem sempre pode ser evidenciada pela análise de DLS. 


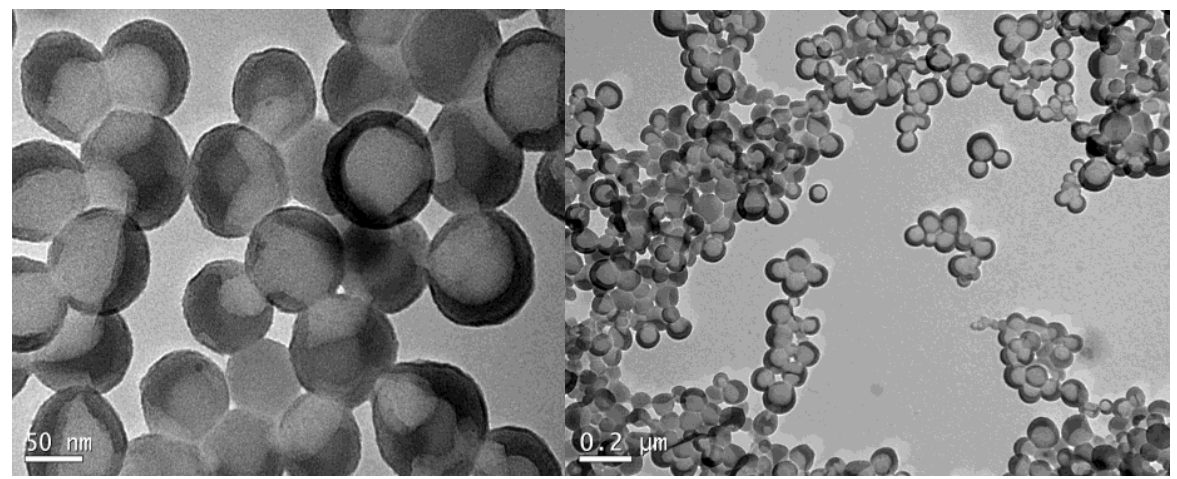

Figura 2 - Micrografia das nanopartículas de PMMA vazias e das nanopartículas de PMMA contendo G12.

Os valores de tamanho médio das partículas e do índice de polidispersão determinados por espalhamento dinâmico de luz, DLS, são apresentados na Tabela 1 e apresentam valores próximos aos observados por MET. Outro fator importante na preparação das nanopartículas poliméricas para aplicação biomédica é o potencial zeta, já que estas influenciam na estabilidade da suspensão de nanopartículas poliméricas e nas interações destas com a membrana celular. A partir desta analise pode-se verificar a estabilidade das nanopartículas. Os dados estão apresentados na tabela abaixo.

Tabela 1 - Diâmetro médio de gotas (Dg) e partículas (Dp), índice de polidispersão (IPD) e carga superficial das nanopartículas de PMMA vazias e das nanoparticulas de PMMA contendo G12.

\begin{tabular}{ccccccc} 
Amostras & Dg $(\mathbf{n m})$ & IPD & Dp $(\mathbf{n m})$ & IPD & Potencial Zeta $(\mathbf{m V})$ & pH \\
\hline PMMA vazias & $88 \pm 1,3$ & 0,09 & $98 \pm 2,5$ & 0,11 & $-37 \pm 2,3$ & $6,97 \pm 0,2$ \\
PMMA/G12 & $95 \pm 2,4$ & 0,14 & $107 \pm 3,1$ & 0,13 & $-35 \pm 3,1$ & $7,01 \pm 0,5$ \\
\hline
\end{tabular}

Os resultados preliminares dos ensaios de citotoxicidade (Figura 3) mostraram que a viabilidade das células leucêmicas, THP-1, tratadas com nanoparticulas de PMMA vazias não foi alterada significativamente quando comparadas ao grupo controle (somente células). Por outro

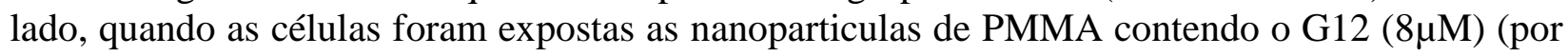
24 horas) ocorreu uma redução da viabilidade de celular de aproximadamente $90 \%$. 


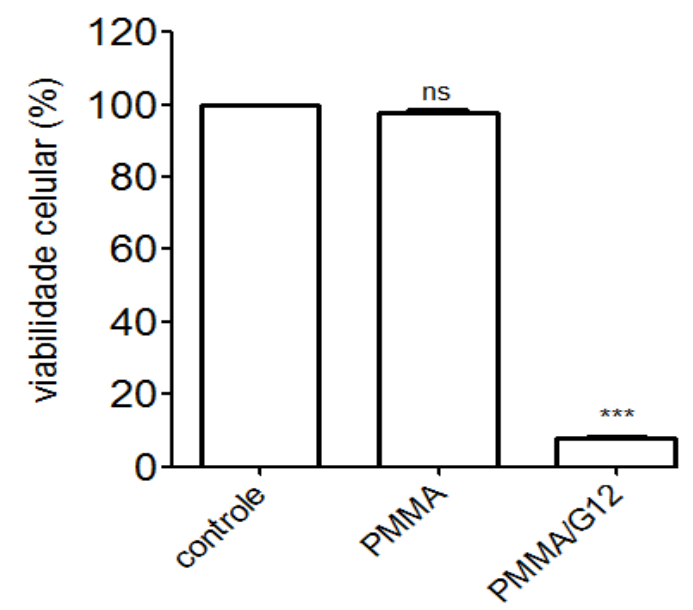

Figura 3 - Avaliação do efeito citotóxico das nanopartículas de PMMA vazias e nanopartículas de PMMA contendo G12 em células leucêmicas THP-1 ( $\mathrm{n}=3)$ (Teste de Bonferrine; ***=p<0,05).

\section{CONCLUSÃO}

O encapsulamento do lauril galato (G12) em nanopartículas de PMMA via polimerização em miniemulsão apresentou resultados satisfatórios. Considerando a uniformidade na distribuição de tamanho de partículas, a, alta estabilidade do sistema e a ausência de citotoxicidade das nanopartículas de PMMA, o método proposto neste trabalho se mostrou eficiente. Nanoparticulas de PMMA contendo G12 na concentração de $8 \mu \mathrm{M}$ ocasionaram uma redução da viabilidade celular de $\sim 90 \%$ em células THP-1. Contudo outros ensaios físico-químicos e in vitro se fazem necessários para avaliar o comportamento das nanopartículas de PMMA contendo o lauril galato.

\section{AGRADECIMENTOS}

Os autores agradecem o auxílio financeiro do CNPq - Conselho Nacional de Desenvolvimento Científico e Tecnológico e da Capes - Coordenação de Aperfeiçoamento Pessoal de Nível Superior e as análises de MET no Laboratório Central de Microscopia Eletrônica da UFSC (LCME).

\section{REFERÊNCIAS}

ABULATEEFEH, S. R.; SPAIN, S. G.; THURECHT, K. J.; AYLOTT, J. W.; CHAN, W. C.; GARNETT, M. C.; ALEXANDER, C. Enhanced uptake of nanoparticle drug carriers via a thermoresponsive shell enhances cytotoxicity in a cancer cell line. Biomater. Sci., v. 1, p. 434442, 2013.

KOIDE, T.; Nose, M.; Inoue,_M.; Ogihara, Y.; Yabu, Y.; Ohta, N. Trypanocidal effects of gallic acid and related compounds. Planta Med., v. 64, n. 1, p.27-30, 1998. 
KOLODZIEJ, H.; RADTKE, O. A.; KIDERLEN, A. F. Stimulus (polyphenol, IFN-c, LPS)dependent nitric oxide production and antileishmanial effects in RAW 264.7 macrophages. Phytochemistry, v.69, p.3103-3110, 2009.

LANDFESTER, K. Structures in Miniemulsion: Miniemulsion Polymerization and the Structure of Polymer and Hybrid Nanoparticles. Angew Chemical, n.48, p. 4488-4507, 2009.

LOCATELLI, C.; ROSSO, R.; SANTOS-SILVA, M. C.; SOUZA, C. A.; LICÍNIO, M. A.; LEAL, P.; BAZZO, M. L.; YUNESD, R. A.; CRECZYNSKI-PASA, T. B. Ester derivatives of gallic acid with potential toxicity toward L1210 leukemia cells. Bioorg. Med. Chem., v. 16, p. 3791-3799, 2008.

LOCATELLI, C.; LEALB, P. C.; YUNESB, R. A.; NUNES, R. J.; CRECZYNSKI-PASAA, T. B. Gallic acid ester derivatives induce apoptosis and cell adhesion inhibition in melanoma cells: The relationship between free radical generation, glutathione depletion and cell death. Chem-Biol Interact., v. 181, p.175-184, 2009.

LOCATELLI, C.; FILIPPIN-MONTEIROC, F. B.; CRECZYNSKI-PASA, T. B. Alkyl esters of gallic acid as anticancer agents: A review. Eur. J. Med. Chem., v. 60, p. 233-239, 2013.

LU, Z.; NIE, G.; BELTON, P. S.; TANG, H.; ZHAO, B. Structure-activity relationship analysis of antioxidant ability and neuroprotective effect of gallic acid derivatives. Neurochemistry International, v. 48, p. 263-274, 2006.

REIS, C. P.; NEUFELD, R. J; RIBEIRO, A. J; VEIGA, F. Nanoencapsulation I. Methods for preparation of drug-loaded polymeric nanoparticles. Nanomedicine: Nanotechnology, Biology and Medicine, n.2, p.8-21, 2006.

SAKAGAMI, H., SATOH, K., HATANO, T., YOSHIDA, T., OKUDA, T.Possible role of radical intensity and oxidation potential for gallic acid-induced apoptosis. Anticancer Res., v. 17, p. 377-380, 1997.

SCHAFFAZICK, S. R.; GUEREEZ, S. S.; FREITAS, L. L.; POHLMANN, A. R. Caracterização e estabilidade Físico-Química de sistemas Poliméricos nanoparticulados para administração de fármacos. Química Nova, v. 26(5), p. 726-737, 2003.

SHORK, F.J., LUO, Y., SMULDERS, W., RUSSUM, J. P., BUTTÉ, A., FONTENOT, K., Miniemulsion Polymerization, Adv. Polym. Sci., v. 175, p. 129-255, 2005.

SOPPIMATH, K. S; AMINABHAVI, T. M; KULKARNI, A. R; RUDZINSKI, E. Journal of Controlled Release. v. 70, p. 1-20, 2001. 